COVID-19

\title{
ENT surgical emergencies during the COVID-19 outbreak
}

\author{
Le urgenze chirurgiche otorinolaringoiatriche durante l'epidemia di COVID-19 \\ Vito Pontillo1, Lucia lannuzzi ${ }^{1}$, Paolo Petrone ${ }^{2}$, Pasqua Irene Sciancalepore ${ }^{1,2}$, Carlo D’Auria ${ }^{3}$, Massimo Rinaldi ${ }^{1,3}$, \\ Giusi Graziano4, Nicola Quaranta ${ }^{1}$ \\ ${ }^{1}$ Otolaryngology Unit, Department of BMS, Neuroscience and Sensory Organs, Policlinico di Bari, University of Bari, Italy; \\ ${ }^{2}$ Otolaryngology Unit, Ospedale Di Venere, Bari, Italy; ${ }^{3}$ Otolaryngology Unit, Ente Ecclesiastico Ospedale Miulli, Acquaviva delle \\ Fonti, Italy; ${ }^{4}$ Biomedical Sciences and Human Oncology Department, University of Bari, Italy
}

\section{SUMMARY}

Introduction. The restrictive measures adopted by the Italian Government during the COVID-19 outbreak caused dramatic changes in routine public health care. Surprisingly, emergency activity also registered a reduction in frequency.

Methods. This multicentre retrospective study aims to investigate eventual changes in ENT surgical emergencies in a highly populated area of southern Italy during the COVID-19 pandemic. Data concerning the period between the February 1 and the May 31, 2020 were collected from the main three hospitals in the district and compared with the same period of 2019.

Results. A substantial reduction was found in the number of ENT emergency interventions in 2020 compared to the same period of 2019, particularly in the main lockdown phase and in the tertiary referral centre.

Conclusions. The reduction in the absolute number of emergency ENT interventions can be only partially explained by social distancing and home confinement. We have reason to believe that some of these patients may have not sought medical support due to fear of nosocomial SARS-CoV2 infection. This study could represent a trigger for further implementation of health system responses to emergencies in a period of transition that is likely to last for a prolonged period of time.

KEY WORDS: COVID-19, outbreak, ENT, emergency, surgery

\section{RIASSUNTO}

Introduzione. Le misure restrittive adottate in Italia durante la pandemia di COVID-19 hanno determinato uno stravolgimento delle attività medico chirurgiche. Inaspettatamente, anche le prestazioni urgenti hanno registrato una riduzione.

Metodi. Abbiamo retrospettivamente confrontato le urgenze chirurgiche ORL eseguite nei tre principali ospedali della Provincia di Bari nel periodo compreso tra il $1^{\circ}$ febbraio e il 31 maggio del 2020 con quelle dello stesso periodo del 2019.

Risultati. È stata riscontrata una importante riduzione nel numero di interventi nel 2020 rispetto all'anno precedente, in particolare nella fase del lockdown vero e proprio e nel centro di riferimento terziario.

Conclusioni. La riduzione del numero di urgenze chirurgiche ORL può essere solo parzialmente spiegata dal distanziamento sociale e dal confinamento domiciliare imposti dalle misure restrittive. Abbiamo motivo di credere che alcuni pazienti potrebbero aver evitato l'assistenza medica per paura di contrarre l'infezione nosocomiale da SARSCoV2. Questo primo studio potrebbe avviare un processo di implementazione del sistema di risposta alle urgenze ORL che sarebbe auspicabile in un periodo di transizione potenzialmente duraturo.

PAROLE CHIAVE: COVID-19, pandemia, ORL, urgenze, chirurgiche
Received: July 31, 2020

Accepted: August 18, 2020

Published online: November 24, 2020

Correspondence

Vito Pontillo

Otorinolaringoiatria Universitaria Policlinico di Bari, Università di Bari, piazza Giulio Cesare 11, 70124 Bari, Italy

Tel. +39080 5592299

E-mail: pontillovito@gmail.com

Funding

None.

\section{Conflict of interest}

The Authors declare no conflict of interest.

How to cite this article: Pontillo V, Iannuzzi L, Petrone P, et al. ENT surgical emergencies during the COVID-19 outbreak. Acta Otorhinolaryngol Ital 2020;40:399-404. https://doi. org/10.14639/0392-100X-N1036

() Società Italiana di Otorinolaringoiatria e Chirurgia Cervico-Facciale

\section{(c) (1) $(9)$}

This is an open access article distributed in accordance with the CC-BY-NC-ND (Creative Commons Attribution-NonCommercial-NoDerivatives 4.0 International) license. The article can be used by giving appropriate credit and mentioning the license, but only for non-commercial purposes and only in the original version. For further information: https:// creativecommons.org/licenses/by-nc-nd/4.0/deed.en 


\section{Introduction}

The COVID-19 pandemic rapidly spread in Europe in the first months of 2020. Italy was one of the first and most affected countries worldwide, with more than 240,000 cases to date. The outbreak mainly struck the northern regions, while the peak was delayed and weakened in middle and southern Italy.

The province of Bari, with more than 1,200,000 inhabitants, is the most populated province in the Puglia region, the third in southern Italy and the seventh in Italy. Thanks to the restrictive measures adopted by the Italian Government, this district was relatively spared by the first COVID-19 outbreak, despite presenting a consistent number of infected people, 1493 at time of writing, almost one-third of all Apulian cases. Nevertheless, the lockdown caused dramatic changes in routine public health care. Surprisingly, even emergency activity has registered a reduction in frequency.

The aim of this study is to investigate changes in ENT surgical emergencies in a highly populated area of southern Italy during the COVID-19 pandemic.

\section{Materials and methods}

This multicentre retrospective study was conducted in the three ENT Units covering all emergencies in the province of Bari: 'Policlinico' (tertiary referral centre), 'Di Venere' and 'Miulli' Hospitals (secondary care centres). While 'Di Venere' Hospital remained COVID-free, 'Policlinico' and 'Miulli' were designated to host COVID-19 patients during the pandemic.

We collected data about ENT surgical emergencies performed between the February 1 and the May 31 for 2020 and 2019. We divided this period into four phases, based on the main restrictive decrees released by the Italian Government (Fig. 1):

- Phase 0 (pre-lockdown);

- Phase 1 (lockdown): starting with the beginning of the restrictive measures (March 9, 2020);

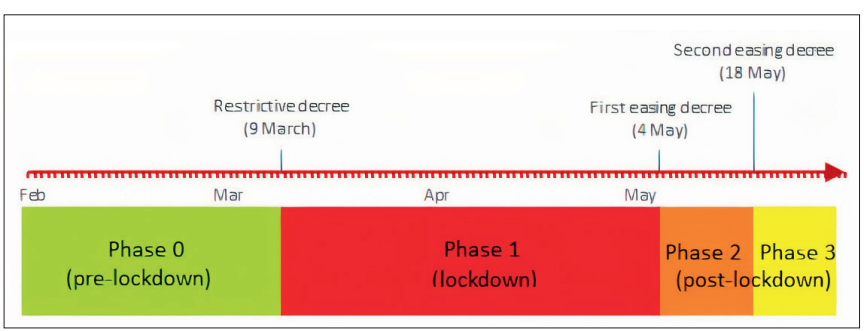

Figure 1. Phases of the study based on the main restrictive and easing decrees by the Italian Government.
- Phase 2 (immediate post-lockdown period): starting with the first and partial relaxation of these measures (May 4, 2020);

- Phase 3 (post-lockdown complete opening): between the $18^{\text {th }}$ (opening decree) and 31st of May 2020.

The same sub-periods were set for 2019.

All procedures were in accordance with the ethical standards of the institutional research committee and with the 1964 Helsinki Declaration and its later amendments or comparable ethical standards. Our Ethics Committee was informed of the retrospective data collection.

Surgical emergencies were divided according to the cause into respiratory, haemorrhagic, suppurative, traumatic and obstructive. Post-operative haemorrhagic complications of elective interventions were the only 'internal emergencies' and were considered separately since this data is strongly influenced by the impairment of scheduled surgery during the outbreak. All 'external' patients were assigned a yellow or red code at the Emergency Department. We retrospectively reclassified priority codes based on our clinical and radiological assessment.

\section{Statistical analysis}

The number of emergency interventions was expressed as absolute number and percentage. Age was expressed as mean \pm sd. Chi-square or Fisher's exact tests and MannWhitney test were used to compare categorical and continuous variables between the two considered periods, respectively. The difference, in terms of surgical interventions, between 2019 and 2020 was calculated as percent change. A p-value $<0.05$ was considered statistically significant. The software R (version 3.5.2) was used for statistical analysis.

\section{Results}

Forty-five surgical emergencies were performed in the study period of 2020, versus 65 interventions performed in 2019, for a reduction of $30.77 \%$ (Tab. I and Fig. 2).

We found a significant reduction $(\mathrm{p}=0.0275)$ in the rate of interventions performed in the tertiary referral centre (35.6\% vs. $61.5 \%$ in 2019 ). On the other hand, the proportion of cases increased in the secondary clinics $(51.1 \%$ and $13.3 \%$ vs. $30.8 \%$ and $7.69 \%$ in 2019 respectively), especially at 'Di Venere', the only COVID-free hospital (Tab. I).

A higher percentage of emergencies was recorded for respiratory ( $31.1 \%$ vs. $26.2 \%$ of 2019$)$ and haemorrhagic conditions ( $11.1 \%$ vs. $6.15 \%$ of 2019$)$, while traumatic $(31.1 \%$ vs. $35.4 \%)$ and infectious causes $(22.2 \%$ vs. $24.6 \%)$ remained stable or slightly reduced (Tab. I). Thus, the pro- 
Table I. Emergency interventions in February-May 2019 and 2020.

\begin{tabular}{|c|c|c|c|}
\hline Variable & 2019 & 2020 & $\mathrm{p}$-value \\
\hline $\mathrm{N}$ & 65 & 45 & \\
\hline Age $($ mean $\pm s d)$ & $48.6 \pm 23.3$ & $52.7 \pm 25.6$ & 0.3856 \\
\hline \multicolumn{4}{|l|}{ Gender $\mathrm{n}(\%)$} \\
\hline $\mathrm{F}$ & $23(35.4)$ & $18(40.0)$ & \multirow{2}{*}{0.6226} \\
\hline M & $42(64.6)$ & $27(60.0)$ & \\
\hline \multicolumn{4}{|l|}{ Care centre N (\%) } \\
\hline Hospital 1 (Policlinico) & $40(61.5)$ & $16(35.6)$ & \multirow{3}{*}{0.0275} \\
\hline Hospital 2 (Di Venere) & $20(30.8)$ & $23(51.1)$ & \\
\hline Hospital 3 (Miulli) & $5(7.7)$ & $6(13.3)$ & \\
\hline \multicolumn{4}{|l|}{ Causes N (\%) } \\
\hline Respiratory & $17(26.2)$ & $14(31.1)$ & \multirow{6}{*}{0.9015} \\
\hline Traumatic & $23(35.4)$ & $14(31.1)$ & \\
\hline Haemorrhagic & $4(6.2)$ & $5(11.1)$ & \\
\hline Post-operative bleeding & $4(6.2)$ & $2(4.4)$ & \\
\hline Infectious & $16(24.6)$ & $10(22.2)$ & \\
\hline Foreign bodies & $1(1.5)$ & $0(0.0)$ & \\
\hline \multicolumn{4}{|l|}{ Subperiods N (\%) } \\
\hline Phase 0 & $17(26.2)$ & $14(31.1)$ & \multirow{4}{*}{0.9381} \\
\hline Phase 1 & $31(47.7)$ & $19(42.2)$ & \\
\hline Phase 2 & $10(15.4)$ & $7(15.6)$ & \\
\hline Phase 3 & 7 (10.8) & $5(11.1)$ & \\
\hline
\end{tabular}

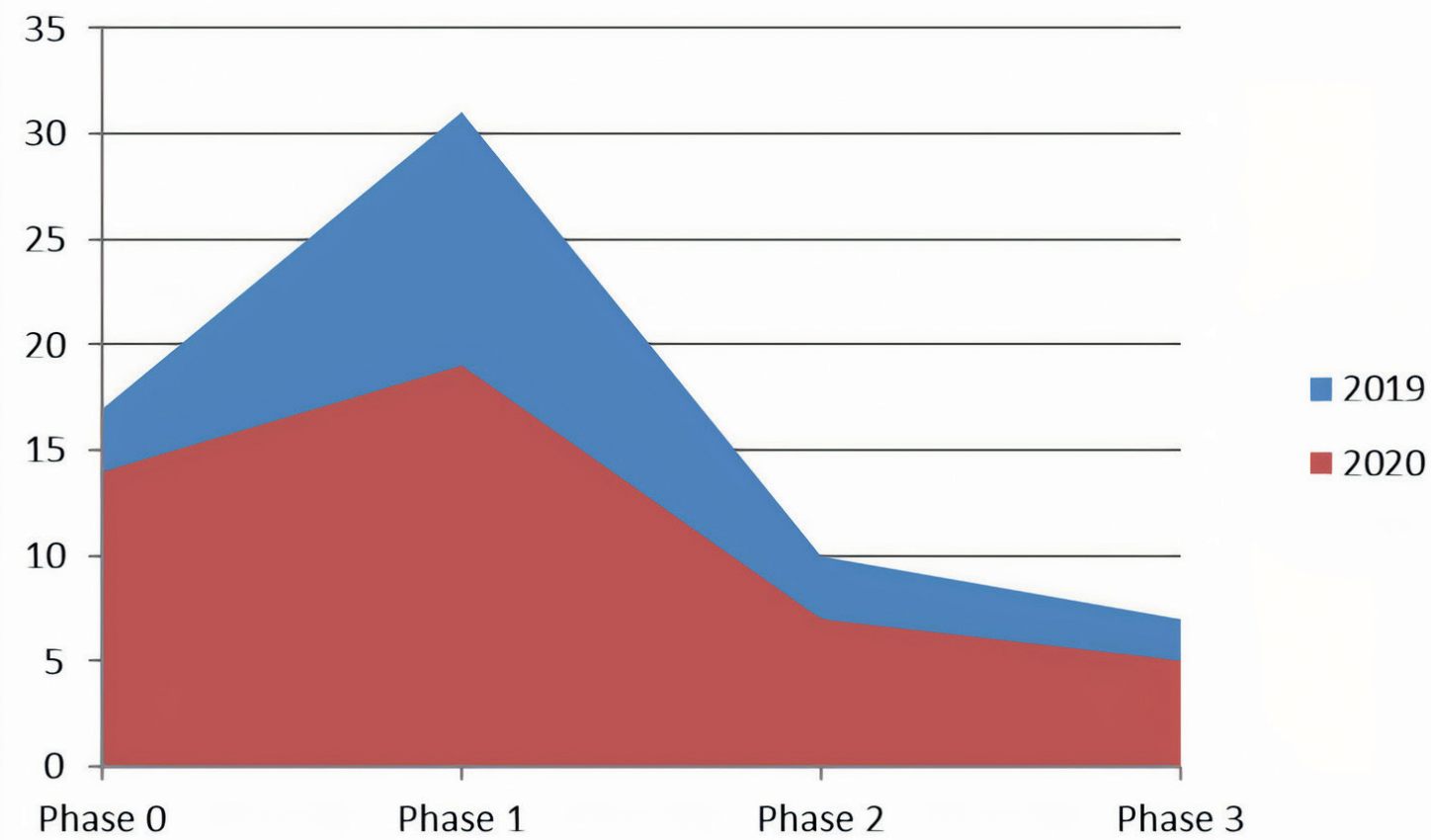

Figure 2. Number of emergency interventions by subperiod in 2019 (blue) and 2020 (red). 
Table II. Emergency interventions in the different hospitals.

\begin{tabular}{|c|c|c|c|c|c|c|}
\hline \multirow[t]{2}{*}{ Causes N (\%) } & \multicolumn{2}{|c|}{ Policlinico } & \multicolumn{2}{|c|}{ Di Venere } & \multicolumn{2}{|c|}{ Miulli } \\
\hline & 2019 & 2020 & 2019 & 2020 & 2019 & 2020 \\
\hline Respiratory & $10(25)$ & $5(31.25)$ & $4(20)$ & $5(21.74)$ & $3(60)$ & $4(66.67)$ \\
\hline Traumatic & $1845)$ & $5(31.25)$ & $4(20)$ & $9(39.13)$ & $1(20)$ & $0(0)$ \\
\hline Haemorrhagic & $2(5)$ & $1(6.25)$ & $2(10)$ & $4(17.39)$ & $0(0)$ & $0(0)$ \\
\hline Post-operative bleeding & $3(7.5)$ & $1(6.25)$ & $1(5)$ & $1(4.35)$ & $0(0)$ & $0(0)$ \\
\hline Infectious & 7 (17.5) & $4(25)$ & $9(45)$ & $4(17.39)$ & $0(0)$ & 2 (33.33) \\
\hline Foreign bodies & $0(0)$ & $0(0)$ & $0(0)$ & $0(0)$ & $1(20)$ & $0(0)$ \\
\hline
\end{tabular}

portion of code red life-threatening emergencies increased from $44.62 \%$ of 2019 to $51.11 \%$ of 2020 .

Table II shows the distribution by cause in the different hospitals.

When considering the different subperiods, we observed a substantial reduction in the number of emergencies in Phase 1, the period of the lockdown (19 cases of $2020 \mathrm{vs.}$ 31 cases of 2019), while we found comparable values in the pre- (Phase 0) and post-lockdown (Phases 2 and 3 ) periods. The lack of statistical significance $(\mathrm{p}=0.93)$ is probably related to the small sample size (Tab. I).

Specifically, a significant reduction $(\mathrm{p}=0.0334)$ in the proportion of interventions performed at 'Policlinico' (Hospital 1) was found in Phase 1 (26.3\% vs. 58.1\% of 2019), again related to a proportional increase at the COVID-free centre $(52.63 \%$ vs. $38.71 \%$ of 2019$)$ (Tab. III). Moreover, the frequency of interventions for traumatic and infective causes halved in this subperiod (4 cases in Phase 12020 vs. 9 cases in Phase 1 2019) (Tab. III).

Surprisingly, a significant change $(p=0.0076)$ in the proportion of emergencies between hospitals was also demonstrated at the end of the lockdown, specifically in Phase 3 (Tab. III).

Finally, we investigated the eventual relation between the rate of emergency ENT interventions and the number of new COVID-19 cases per week in the same province. As represented in Figure 3, a fall in the number of interventions was observed in the two weeks (23-29 March and 30 March - 5 April) in which the highest number of new COVID-19 patients was registered (287 and 272 respectively).

\section{Discussion}

The COVID-19 pandemic has rapidly spread in Italy, and is strongly influenced by socio-demographic characteristics. The province of Bari is one of the most populated districts in Italy, and thus predictions in terms of pandemic spread and strain on public health care were not promising. Southern Italy was partially spared by the outbreak since the re- strictive measures by the Italian Government anticipated possible negative evolutions. These measures impacted both people's lifestyle and public health care routine. In particular, ENT elective activity was deeply affected by the outbreak and various national and international scientific societies proposed best-practice recommendations in order to adapt elective clinical and surgical activity during pandemic conditions ${ }^{1-5}$. Italian societies have also recently published their strategic plan for management of surgical patients in the current era ${ }^{6,7}$.

Gelardi et al. ${ }^{8}$ reported an important decrease in emergency ENT consultations (80.8\%) in the Apulia region during the COVID-19 pandemic. However, to our knowledge the impact of the lockdown on ENT emergency surgical activity has not been previously analysed.

Our analysis showed a reduction in the number of ENT surgical emergencies in the entire province in the months of the outbreak (February-May). The major reduction registered in the tertiary referral centre, specifically during the main lockdown (Phase 1), is probably to put in relation to the fact that a large part of the workforce and spaces were dedicated to the care of COVID-19 patients and some of the emergencies were rerouted to secondary centres. Surprisingly, similar results were also found in the post-lockdown period (Phase 3), when all hospitals were gradually returning to routine activity. We have reason to believe that this could be imputable to the patients' preference to present to COVID-free hospitals for fear of the virus.

It appears obvious that home confinement, traffic restriction and social distancing inevitably reduced the incidence of traumas, common cold and other upper respiratory tract viral or bacterial infections, together with their eventual evolutions. Additionally, the worry about the risk of nosocomial infection probably contributed to the reduction in medical demand in hospitals.

In fact, in our series the proportion of life-threatening respiratory and haemorrhagic emergencies increased during the pandemic, while interventions for traumatic and infectious diseases remained unchanged with respect to the 


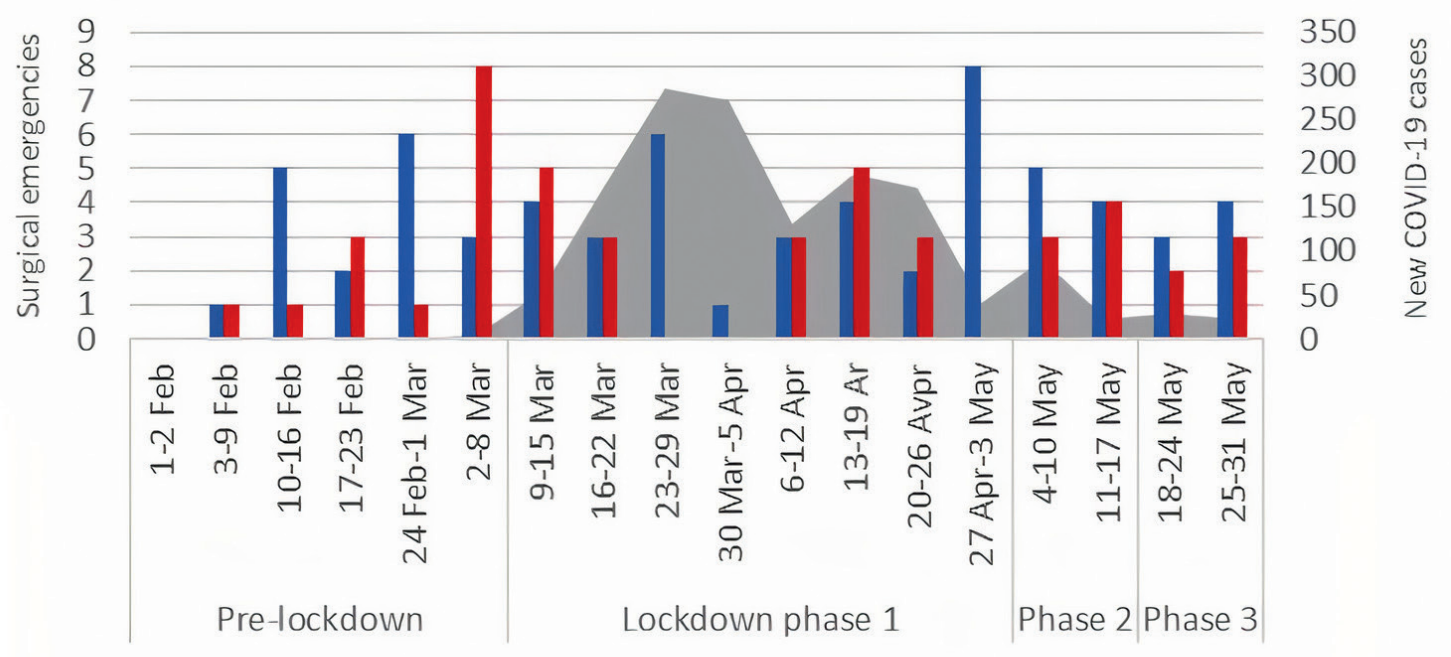

new recorded COVID-19 cases per week in the Province of Bari

Number of ENT surgical emergencies 2019

Number of ENT surgical emergencies 2020

Figure 3. Graphical representation of the relationship between surgical emergencies and new COVID-19 cases per week in the Province of Bari.

Table III. Emergency interventions in the different subperiods categorised by hospital and cause.

\begin{tabular}{|c|c|c|c|c|c|c|c|c|c|c|c|c|}
\hline \multirow[t]{2}{*}{ Variable } & \multicolumn{3}{|c|}{ Phase 0} & \multicolumn{3}{|c|}{ Phase 1} & \multicolumn{3}{|c|}{ Phase 2} & \multicolumn{3}{|c|}{ Phase 3} \\
\hline & 2019 & 2020 & p-value & 2019 & 2020 & $\mathrm{p}$-value & 2019 & 2020 & p-value & 2019 & 2020 & p-value \\
\hline $\mathrm{N}$ & 17 & 14 & & 31 & 19 & & 10 & 7 & & 7 & 5 & \\
\hline $\begin{array}{l}\text { Hospital } 1 \\
\text { (Policlinico) }\end{array}$ & $8(47.06)$ & $8(57.14)$ & & $\begin{array}{c}18 \\
(58.06)\end{array}$ & 5 (26.32) & & $8(80)$ & $3(42.86)$ & & $6(85.71)$ & 0 & \\
\hline $\begin{array}{l}\text { Hospital } 2 \\
\text { (Di Venere) }\end{array}$ & $5(29.41)$ & $5(35.71)$ & 0.5593 & $\begin{array}{c}12 \\
(38.71)\end{array}$ & $\begin{array}{c}10 \\
(52.63)\end{array}$ & 0.0334 & $2(20)$ & $4(57.14)$ & 0.9825 & $1(14.29)$ & $4(80)$ & 0.0076 \\
\hline Hospital 3 (Miulli) & $4(23.53)$ & $1(7.14)$ & & 1 (3.23) & $4(21.05)$ & & 0 & 0 & & 0 & $1(20)$ & \\
\hline \multicolumn{13}{|l|}{ Causes, N (\%) } \\
\hline Respiratory & $4(23.53)$ & $3(21.43)$ & & $9(29.03)$ & $8(42.11)$ & & $2(20)$ & $2(28.57)$ & & $2(28.57)$ & $1(20)$ & \\
\hline Traumatic & $5(29.41)$ & $5(35.71)$ & & $9(29.03)$ & $4(21.05)$ & & $5(50)$ & $2(28.57)$ & & $4(57.14)$ & $3(60)$ & \\
\hline Haemorrhagic & $1(5.88)$ & $1(7.14)$ & & $2(6.45)$ & $2(10.53)$ & & $1(10)$ & $1(14.29)$ & & 0 & $1(20)$ & \\
\hline Foreign bodies & $1(5.88)$ & 0 & & 0 & 0 & & 0 & 0 & & 0 & 0 & \\
\hline
\end{tabular}

same period of 2019. Most of our trauma patients were treated for nasal bone fracture, a non-life threatening and optionable condition that certainly registered a decline during the outbreak. On the other hand, the reduction in the percentage of emergency intervention for infectious diseases, especially in Phase 1 (4 cases vs. 9 cases of 2019) may be partially explained by home confinement and social distancing, at least for bacterial suppurations that are 
secondary to upper respiratory tract infections. However, the quota of odontogenic neck infections should have been unchanged since it does not depend on social and environmental exposition. Our theory is that a part of these subjects may have ignored the problem for fear of nosocomial SARS-COV2 contagion. No data are available about the possible outcomes of these individuals, but a future focus on the cause of deaths during this pandemic could help to explain this phenomenon.

Figure 3 probably confirms the hypothesis of the role that was played by the population's risk perception on the number of surgical emergencies. Daily bulletins released by local authorities and mass-media about the new infected cases certainly improved people's compliance to restrictions, but they might have indirectly influenced their tendency to see physicians for other diseases, as confirmed by other authors ${ }^{9,10}$.

\section{Conclusions}

The main limit of our study is the small number of cases and its poor relevance in comparison to other regions where the outbreak was much more severe. Further studies could be useful to verify if the same conditions were recorded in other regions, especially in those most struck by the pandemic. An online survey addressed to all Italian otolaryngologists could help gain knowledge about behaviours in surgical emergency care during the COVID-19 pandemic. In fact, in consideration of the imminent risk of new COVID-19 waves in Italy and Europe, this study could represent a trigger for the realisation of new strategies to improve the health system response to an emergency in a period of transition that is likely to last for a prolonged period of time. The individuation of specific no-COVID-19 centres dedicated to emergencies and reinforcement of telemedicine strategies may allow early detection and treatment of ENT emergencies.

\section{Acknowledgements}

We thank the medical and paramedical staff of the three hospitals for participating in elective and emergency activity during the COVID-19 outbreak. We would also like to show our gratitude to the University of Bari for the support and for providing all the scientific material for the research. All data and material are available and can be provided if requested.

\section{References}

1 Bann DV, Patel VA, Saadi R, et al. Impact of coronavirus (COVID-19) on otolaryngologic surgery: brief commentary. Head Neck 2020;42:1227-34. https://doi.org/10.1002/hed.26162

2 Couloigner V, Schmerber S, Nicollas R, et al. COVID-19 and ENT Surgery. Eur Ann Otorhinolaryngol Head Neck Dis 2020;137:161-6. https://doi.org/10.1016/j.anorl.2020.04.012

3 Mehanna H, Hardman JC, Shenson JA, et al. Recommendations for head and neck surgical oncology practice in a setting of acute severe resource constraint during the COVID-19 pandemic: an international consensus. Lancet Oncol 2020;21:e350-9. https://doi.org/10.1016/ S1470-2045(20)30334-X

4 Lescanne E, van der Mee-Marquet N, Juvanon JM, et al. Best practice recommendations: ENT consultations during the COVID-19 pandemic. Eur Ann Otorhinolaryngol Head Neck Dis 2020;137:303-8. https:// doi.org/10.1016/j.anorl.2020.05.007

5 Radulesco T, Verillaud B, Béquignon E, et al. COVID-19 and rhinology, from the consultation room to the operating theatre. Eur Ann Otorhinolaryngol Head Neck Dis 2020;137:309-14. https://doi. org/10.1016/j.anorl.2020.04.013

6 Quaranta N, Pantaleo A, Berrettini S, et al. Strategic plan for the management of ENT and maxillofacial patients during the post-pandemic transition period (SIOeChCF). https://www.sioechcf.it/piano-strategico-per-la-gestione-del-paziente-orl-durante-il-periodo-di-transizione-a-seguito-della-pandemia-covid-19-versione-2. Accessed 6 July 2020.

7 Castelnuovo P, Turri-Zanoni M, Karligkiotis A, et al. Skull-base surgery during the COVID-19 pandemic: the Italian Skull Base Society recommendations. Int Forum Allergy Rhinol 2020;10:963-7. https:// doi.org/10.1002/alr.22596

8 Gelardi M, Iannuzzi L, Trecca EMC, et al. COVID-19: what happened to all of the otolaryngology emergencies? Eur Arch Otorhinolaryngol 2020;277:3231-2. https://doi.org/10.1007/s00405-020-06046-Z

9 Pessoa-Amorim G, Camm CF, Gajendragadkar P, et al. Admission of patients with STEMI since the outbreak of the COVID-19 pandemic. A survey by the European Society of Cardiology. Eur Heart J Qual Care Clin Outcomes 2020;6:210-6. https://doi.org/10.1093/ehjqcco/ qcaa046

10 De Rosa S, Spaccarotella C, Basso C, et al. Reduction of hospitalizations for myocardial infarction in Italy in the COVID-19 era. Eur Heart J 2020;41:2083-8. https://doi.org/10.1093/eurheartj/ehaa409 